\title{
http://ejournal.universitasmahendradatta.ac.id/index.php/satyagraha ANALISIS MARKETING MIX PADA PRODUK INDOMIE DI KOTA BIMA
}

\author{
Sri Ernawati \\ Prodi Manajemen, Sekolah Tinggi Ilmu Ekonomi Bima \\ sriernawati.stiebima@.gmail.com
}

\begin{abstract}
Abstrak- Penelitian ini bertujuan untuk mengetahui Bauran pemasaran produk pada produk Indomie di Kota Bima. Jenis penelitian yang digunakan yaitu deskriptif, lokasi penelitian di Kota Bima. Populasi dalam penelitian inin adalah semua konsumen yang pernah membeli produk Indomie, sampel dalam penelitian ini berjumlah 100 orang dengan teknik purposive sampling. Instrumen penelitian menggunakan quesioner dengan pengukuran skala likert Adapun jenis data yang digunakan dalam penelitian ini adalah data kuantitatif dengan sumber data penelitian yaitu data primer. Teknik pengumpulan data yaitu observasi, angket/koesioner dan studi pustaka. Analisis data menggunakan t test one sampel. Hasil penelitian menunjukan bahwa Bauran pemasaran produk pada produk Indomie di Kota Bima di atas kriteria yang telah ditetapkan $75 \%$ (Baik)
\end{abstract}

Kata Kunci : Bauran Pemasaran, Produk, Harga, Promosi, Tempat

Abstract- This study aims to determine the product marketing mix of Indomie products in the city of Bima. The type of research used is descriptive, the research location is in the city of Bima. The population in this study are all consumers who have bought Indomie products, the sample in this study amounted to 100 people with a purposive sampling technique. The research instrument used a questionnaire with a Likert scale measurement. The type of data used in this study was quantitative data with the research data source, namely primary data. Data collection techniques are observation, questionnaires and literature study. Data analysis using one sample $t$ test. The results showed that the product marketing mix of Indomie products in Bima City was above the predetermined criteria of $75 \%$ (Good)

Keyword : Marketing Mix, products, pricing, promotion, place 
Jurnal Satyagraha

Vol.04, No.01, Pebruari 2021 - Agustus 2021

ISSN : 2620-6358

\section{PENDAHULUAN}

Setiap usaha tentunya harus memiliki strategi

pemasaran yang harus dijalankan dalam

melaukan kegitan bisnisnya. Strategi

merupakan sarana untuk suatu usaha yang

digunakan untuk mencapai suatu tujuan.

Salah satu bentuk strategi bisnis adalah

strategi pemasaran.. Pemasaran merupakan

salah satu kegiatan yang sangat penting

dalam dunia usaha. Pada kondisi usaha

seperti sekarang ini, pemasaran merupakan

pendorong untuk meningkatkan penjualan

sehingga tujuan suatu usaha dapat tercapai.

Pengetahuan mengenai pemasaran menjadi penting bagi para pelaku usaha pada saat dihadapkan pada beberapa permasalahan, seperti menurunnya pendapatan suatu usaha yang disebabkan oleh menurunnya daya beli konsumen terhadap suatu produk sehingga mengakibatkan melambatnya pertumbuhan suatu usaha. Persaingan yang semakin luas menyebabkan harus adanya strategi

pemasaran yang dapat membuat usahanya tetap berkembang. Banyak strategi yang bisa digunakan untuk meningkatkan penjualan dan menarik konsumen untuk membeli produk yang ditawarkan oleh produsen. Salah satu strategi yang banyak digunakan oleh perusahaan adalah marketing mix strategy (strategi bauran pemasaran). (Poluan et all, 2019)

Kegiatan pemasaran di era bisnis sekarang merupakan faktor yang penting untuk mempertahankan dan mengembangkan usaha. Semakin tinggi tingkat persaingan dalam bisnis, mengharuskan pihak manejemen untuk melakukan inovasi dalam usaha untuk mempertahankan pelangganpelanggannya. Kegiatan ini untuk menciptakan pelanggan-pelanggan yang loyal. Loyalitas dari pelanggan sangatlah penting bagi kelangsungan dan pertumbuhan sebuah perusahaan. (Leawati\&Sulistiadi, 2018)

Marketing Mix merupakan bauran pemasaran yang dapat digunakan oleh Perusahaan untuk menciptakan penjualan sesuai dengan pasar sasaran yang dituju. Bauran tersebut adalah Produk (product), Harga (price), Distribusi (distribution) dan Promosi (promotion). Perusahaan harus menyelaraskan keempat bauran tersebut dalam usaha untuk mencapai tingkat penjualan yang diinginkan . Artinya jika pasar sasaran yang ingin dituju adalah kalangan atas yang memiliki duit, maka produk harus berkualitas dan bergengsi, harga harus premium, penampilan gerai eksklusif dan media promosi serta pesan yang ditampilkan juga menunjukan kelas atas.( Benyamin, 2019)

Salah satu strategi pemasaran terpadu adalah bauran pemasaran (Assauri, 2014). Bauran pemasaran merupakan seperangkat alat yang dapat digunakan pemasar untuk membentuk karakteristik jasa yang ditawarkan kepada pelanggan. Alat-alat tersebut dapat digunakan untuk menyusun strategi jangka panjang dan program jangka pendek. Unsur-unsur bauran pemasaran yakni products, pricing, promotion, place. Produk (baik berwujud fisik maupun jasa) yang ditawarkan kepada pelanggan untuk memenuhi kebutuhan pelanggan. Harga pada pelayanan jasa menjadi indikator signifikan terhadap kualitas. Promosi meliputi berbagai metode mengkomunikasikan manfaat jasa kepada pelanggan. Tempat menyangkut kemudahan akses terhadap jasa bagi pelanggan. Petugas merupakan unsur vital dalam bauran pemasaran oleh karena itu organisasi jasa harus secara jelas menentukan apa yang diharapkan dari karyawan dalam interaksinya dengan pelanggan. Proses 
http://ejournal.universitasmahendradatta.ac.id/index.php/satyagraha

merupakan prosedur dalam pelayanan jasa. Bukti fisik merupakan upaya mengurangi tingkat resiko persepsi konsumen terhadap pelayanan jasa. Layanan fasilitas merupakan kualitas total jasa yang dipersepsikan oleh pelanggan (Tjiptono, 2014).

Perusahaan terus berusaha untuk meningkatkan kepuasan pelanggan agar pelanggan mau membeli kembali produk tersebut terus menerus, salah satu strategi pemasaran yang dapat dilakukan perusahaan untuk meningkatkan kepuasan konsumen dan niat pembelian ulang adalah bauran pemasaran (marketing mix). Bauran pemasaran (marketing mix) adalah seperangkat alat pemasaran yang digunakan perusahaan untuk terus menerus mencapai tujuan pemasarannya di pasar sasaran (Tejantara \& Sukawati, 2018)

Indomie adalah merek mie instan yang diproduksi oleh Indofood CBP. Ketika mie instan pertama kali diperkenalkan kepada masyarakat Indonesia di tahun 1969, banyak yang meragukan bahwa mi instan dapat dijadikan sebagai salah satu bahan pangan pokok. Akan tetapi, karena mi instan sendiri harganya relatif terjangkau, mudah disajikan dan awet, Indomie berkembang pesat seiring dengan diterimanya mi instan di Indonesia. Produk Indomie yang pertama kali diperkenalkan adalah Indomie Kuah Rasa Kaldu Ayam yang saat itu sesuai dengan selera lidah masyarakat Indonesia. Kemudian pada tahun 1982, penjualan produk Indomie mengalami peningkatan yang sangat signifikan dengan diluncurkannya varian Indomie Kuah Rasa Kari Ayam. Puncaknya pada tahun 1983, Produk Indomie kembali semakin digemari oleh masyarakat Indonesia dengan diluncurkannya varian Indomie Mi Goreng.( indomie.co.id)

Produk indomie di Kota Bima banyak disukai selain produk yang mudah didapat, harga juga bersaing dengan kualitas produk yang tinggi dari produk mie instan yang lain seperti mie sedap, sakura, sarimi dan lainlain. Keinginan masyarakat menggunakan indomei bisa terlihat dari produk indomie yang selalu berada di kios-kios kecil maupu mini market, ini membuktikan dimana pun masyarakat membutuhkan produk Indomie pasti bisa dengan mudah didapatkan dan promosi yang dilakukan oleh perusahaan Indofood CPB selalu bisa menarik hati konsumen untuk membelinya karena selalu ditayangkan dimedia cetak maupun elektronik.

\section{Bauran Pemasaran (Marketing Mix) \\ Menurut Assauri}

(2013:75)

mendefinisikan "Bauran pemasaran (marketing mix) merupakan kombinasi variabel atau kegiatan yang merupakan inti dari sistem pemasaran, yaitu variabel yang dapat dikendalikan oleh perusahaan untuk mempengaruhi reaksi para pembeli atau konsumen". Dalam bauran pemasaran terdapat empat jenis yang biasa disebut $4 \mathrm{P}$ yaitu produk (product), harga (price), promosi (promotion), tempat (place). Adapun pengertian dari masing-masing bauran pemasaran adalah sebagai berikut :

1. Produk

Menurut Tjiptono (2015:231) produk adalah "Pemahaman subyektif produsen atas sesuatu yang bisa ditawarkan sebagai usaha untuk mencapai tujuan organisasi melalui pemenuhan kebutuhan dan keinginan konsumen sesuai dengan kompetensi dan kapasitas organisasi serta daya beli pasar". Alma (2013:139) mendefinisikan "produk sebagai seperangkat atribut baik berwujud maupun tidak berwujud, termasuk di dalamnya masalah warna, harga, nama baik pabrik, nama baik toko yang menjual (pengecer), dan pelayanan pabrik serta pelayanan pengecer, yang diterima oleh pembeli guna memuaskan keinginannya". Menurut Kotler dan Keller (2016) ada beberapa item-item untuk menentukan 
http://ejournal.universitasmahendradatta.ac.id/index.php/satyagraha

produk yaitu, fitur, kesesuaian dengan keinginan, keandalan serta desainnya.

2. Harga

Kotler \& Amstrong (2016:324) "harga merupakan sejumlah uang uang yang dikeluarkan untuk sebuah produk atau jasa, atau sejumlah nilai yangditukarkan oleh konsumen untuk memperoleh manfaat atau kepemilikan atau penggunaan atas sebuah produk atau jasa". Menurut kotler dan Armstrong (2016), ada empat komponenkomponen untuk menentukan harga yaitu keterjangkauan harga, kesesuaian harga dengan kualitas, daya saing harga, kesesuaian harga dengan manfaat.

3. Promosi

Menurut Tjiptono (2015, p.387) promosi merupakan elemen bauran pemasaran yang berfokus pada upaya menginformasikan, membujuk, dan mengingatkan kembali konsumen akan merek dan produk perusahaan. Menurut Kotler dan Armstrong (2016) item-item promosi yaitu periklanan, promosi penjualan, penjualan perseorangan, hubungan masyarakat, penjualan langsung.

4. Lokasi

Menurut Suwarman (2011:280) "Lokasi merupakan tempat usaha yang sangat mempengaruhi keinginan seseorang konsumen untuk datang dan berbelanja". Menurut (Tjiptono, 2015) komponenkomponen untuk menentukan lokasi yaitu akses, tempat paerkir yang luas, lingkungan, persaingan.

Hipotesis adalah jawaban sementara yang bersifat sementara terhadap permasalahan peneliti sampai bukti melalui data yang terkumpul (sugiyono, 2017). Maka peneliti mengajukan hipotesis sebagai berikut :

\section{Hipotesis penelitian}

Diduga bauran pemasaran pada produk Indomie Kota Bima diatas kriteria yang telah ditetapkan $75 \%$ (Baik).
Hipotesis statistik

$\mathrm{H}_{0}: \mu \geq 75 \%$ : Diduga bauran pemasaran produk Indomie di Kota Bima dibawah kriteria yang telah ditetapkan 75\% (tidak Baik).

$\mathrm{H}_{a}: \mu<75 \% \quad$ : Diduga bauran pemasaran produk pada produk Indomie di Kota Bima di atas kriteria yang telah ditetapkan 75\% (Baik)

\section{METODE PENELITIAN}

Analisis deskriptif adalah metode yang digunakan untuk menggambarkan atau menganalisis suatu hasil penelitian tetapi tidak digunakan untuk membuat kesimpulan yang lebih luas (Sugiyono 2017:147). Jenis penelitian ini adalah penelitian dekskriptif yang menunjukan dugaan tentang satu variable tanpa membuat perbandingan yaitu analisis bauran pemasaran pada produk Indomie di Kota Bima

Populasi adalah keseluruhan subjek penelitian atau objek yang diteliti. Populasi dalam penelitian ini adalah seluruh konsumen yang pernah membeli produk Indomie di Kota Bima yang jumlahnya tidak diketahui (unknown population) dengan jumlah sampel 100 orang. Teknik sampling dalam penelitian ini adalah purposive sampling. Skala pengukuran data dalam penelitian ini adalah skala likert sebagai alat untuk mengukur sikap, pendapat dan persepsi seseorang atau kelompok orang tentang fenomena sosial. Dalam melakukan penelitian terhadap variabel-veariabel yang akan diuji pada setiap jawaban akan di beri skor 1-5. Tehnik pengumpulan data dengan menggunakan observasi, kuesioner dan studi pustaka. Pengujian instrumen menggunakan uji validitas dan reliabilitas Analisis data menggunakan dengan menggunakan t-test one sampel dengan 
menggunakan SPSS versi 20.

http://ejournal.universitasmahendradatta.ac.id/index.php/satyagraha

\section{HASIL DAN PEMBAHASAN}

Uji Validitas dan Uji Reabilitas

\section{Uji Validitas}

Hasil pengujian Uji Validitas yang di lakukan dengan menggunakan Program SPSS versi 20, Menunjukan hasil sebagai berikut :

Tabel 1. Hasil Uji Validitas

\begin{tabular}{llccl}
\hline Variabel & Pernyataan & $\mathrm{r}$ hit & $\mathrm{r}$ tab & Ket \\
\hline Marketing & Item 1 & .751 & .300 & Valid \\
Mix & Item 2 & .652 & .300 & Valid \\
& Item 3 & .697 & .300 & Valid \\
& Item 4 & .760 & .300 & Valid \\
& Item 5 & .704 & .300 & Valid \\
& Item 6 & .610 & .300 & Valid \\
& Item 7 & .707 & .300 & Valid \\
& Item 8 & .602 & .300 & Valid \\
& Item 9 & .687 & .300 & Valid \\
& Item 10 & .632 & .300 & Valid \\
& Item 11 & .689 & .300 & Valid \\
& Item 12 & .706 & .300 & Valid
\end{tabular}

Sumber data : data yang diolah SPSS 20.
Berdasarkan tabel 1 di atas, hasil pengujian validitas variabel Kualitas Produk dan Harga dan keputusan pembelian produk tenun di kota Bima dapat dikatakan valid pada Corrected item-total correlation $>0,300$. Hasil pengujian validitas ini menunjukkan bahwa pernyataan kuesioner dalam penelitian ini valid.

2. Uji Reabilitas

Tabel 2. Hasil Uji Reabilitas

\begin{tabular}{llll}
\hline Variabel & $\begin{array}{l}\text { Cronbach's } \\
\text { alpha }\end{array}$ & Ket \\
\hline $\begin{array}{l}\text { Marketing } \\
\text { Mix }\end{array}$ & 0,897 & 0,600 & Reliabel \\
Sumber data : data yang diolah SPSS 20. \\
Hasil pengujian penelitian \\
menggunakan pengukuran ini dapat \\
dikatakan reliabel pada Cronbach alpha> \\
0,600. Hasil pengujian reliabilitas ini \\
menunjukkan bahwa pernyataan quesioner \\
dalam penelitian ini reliable
\end{tabular}

3. Uji T test one sample

Tabel 3. Uji Hipotesis

One-Sample Test

\begin{tabular}{|c|c|c|c|c|c|c|}
\hline \multicolumn{7}{|c|}{ One-Sample Test } \\
\hline & \multicolumn{6}{|c|}{ Test Value $=0.75$} \\
\hline & \multirow[t]{2}{*}{$\mathrm{t}$} & \multirow[t]{2}{*}{ df } & \multirow[t]{2}{*}{$\begin{array}{l}\text { Sig. } \\
(2- \\
\text { tailed })\end{array}$} & \multirow[t]{2}{*}{$\begin{array}{c}\text { Mean } \\
\text { Difference }\end{array}$} & \multicolumn{2}{|c|}{$\begin{array}{l}95 \% \text { Confidence } \\
\text { Interval of the } \\
\text { Difference }\end{array}$} \\
\hline & & & & & Lower & Upper \\
\hline $\begin{array}{l}\text { Marketing } \\
\text { Mix }\end{array}$ & 83.869 & 99 & .000 & 47.49000 & 46.3665 & 48.6135 \\
\hline
\end{tabular}

Sumber Sumber data : data yang diolah SPSS 20. 
Jurnal Satyagraha

Vol.04, No.01, Pebruari 2021 - Agustus 2021

ISSN : 2620-6358

http://ejournal.universitasmahendradatta.ac.id/index.php/satyagraha

Dari tabel diatas, perhitungan t-test satu sampel dengan nilai $\mu_{0}=75 \%$, serta tingkat signifikasi 0.05 pada uji pihak kiri dengan mengunakan SPSS versi 20. Dalam penelitian ini di ketahui $\mathrm{n} 1=100$ sehingga di gunakan rumus t-test satu sampel. Nilai $t_{\text {tabel }}$ dapat di hitung dengan menggunakan $\mathrm{dk}=\mathrm{n}-1$ $(100-1=99)$ dengan derajat kesalahan $5 \%$ $(0,05)$, maka di peroleh nilai $t_{\text {tabel }}=1,66039$, nilai t hitung 83.869 karena nilai thitung lebih besar dari $t_{\text {tabel }}(83.869>1,66039)$ maka jatuh pada daerah penerimaan $\mathrm{H}_{a}$ artinya $\mathrm{H}_{\mathrm{a}}$ terima dan $\mathrm{H}_{0}$ di tolak. Hal tersebut menjawab dan membuktikan hipotesis $\operatorname{Nol}\left(\mathrm{H}_{\mathrm{a}}\right)$ yang menyatakan bahwa Bauran pemasaran produk pada produk Indomie di Kota Bima di atas kriteria yang telah ditetapkan $75 \%$ (Baik)

\section{PENUTUP}

Dari uji validitas di nyatakan bahwa variabel bauran pemasaran pada produk Indomie di Kota Bima pada keseluruhan instrumen yang di gunakan di nyatakan Valid, karena $>0.300$. Dari uji reabilitas di nyatakan bahwa bauran pemasaran pada produk Indomie di Kota Bima dengan indikator produk, harga, promosi dan lokasi, dapat dikatakan memenuhi harapan pelanggan atau reliabel $>0.600$. Dari uji analisa stratistik bauran pemasaran pada produk Indomie di Kota Bima di atas kriteria yang telah di tetapkan $75 \%$ (Baik)

\section{DAFTAR PUSTAKA}

Alma, Buchari. 2013. Manajemen Pemasaran dan Pemasaran Jasa. Bandung: Alfabeta.
Benyamin Putra arie, 2019. Strategi Bauran Pemasaran (Marketing Mix Strategy) di Pasarkita Pamulang . Jurnal Pemasaran Kompetitif. Vol. 2 No. 3.

Kotler, Philip and Gary Amstrong. (2016). Prinsip-prinsip Pemasaran. Edii13. Jilid 1. Jakarta:Erlangga

Kotler, Philip and Kevin Lane Keller, 2016. Marketing Managemen, 15th Edition, Pearson Education,Inc.

Leawaty\& Sulistiadi Wahyu, 2018. Hubungan Bauran Pemasaran (Marketing Mix) Dengan Loyalitas Pelanggan: Systematic Review. Jurnal ARSI. Volume 5 Nomor 1

Poluan Firna M.A, Mandey Silvya L \& Ogi Imelda W.J, 2019. Strategi Marketing Mix Dalam Meningkatkan Volume Penjualan (Studi Pada Minuman Kesehatan Instant Alvero) . Jurnal EMBA. Vol.7 No.3 Juli 2019, Hal. $2969-2978$

Sugiyono. (2017). Metode Penelitian Kuantitatif, Kualitatif, dan R\&D. Bandung : Alfabeta, CV.

Tejantara Andy \& Sukawati Tjok Gde Raka, 2018. Pemasaran Terhadap Kepuasan Pelanggan Untuk Meningkatkan Niat Pembelian Ulang (Studi Pada Oli Sepada Motor Merek Eni Di Kota Denpasar). E-Jurnal Manajemen Unud, Vol. 7, No. 10

Tjiptono, Fandy. 2014, Pemasaran Jasa Prinsip, Penerapan, dan Penelitian, Andi Offset, Yogyakarta.

-------. 2015, Strategi Pemasaran, Andi Offset, Yogyakarta. 